\title{
Numerical Simulation of Sliding Processes of Yigong Landslide Subjected to Seismic Loading
}

\author{
Ziyin CAI and Enlong LIU ${ }^{1}$ \\ State Key Laboratory of Hydraulics and Mountain River Engineering College of Water \\ Resource \& Hydropower, Sichuan University, Chengdu, China
}

\begin{abstract}
The Yigong landslide is simulated and analyzed with a combined finitediscrete method (FDEM) under seismic loading. Determination of computing model and parameters are introduced. The final distances of six reference points are given showing a special distribution in accord with the results of field investigation. Also, the velocity time-history curves of these points are depicted, where two trends are captured for these points matching with the sliding process of the Yigong landslide. Inconsistencies of displacements and velocities of these points result from the generation and propagation of cracks, initiating the landslide eventually. The FDEM works well in the simulation of this landslide, revealing its applicability and advantages.
\end{abstract}

Keywords. FDEM, Dynamic analysis, Yigong landslide.

\section{Introduction}

The Yigong landslide occurred in Tibet, China in April 2000, damming the Yigong Zangpo River and leading to an enormous and devastating flood. In the Yigong region, River erosion has formed a high mountain and deep canyon terrain and seismic activities are frequent. Long-runout landslides frequently occur in such a region, causing a series of disasters and threatening human life. Therefore, it's reasonable and significant to study the initiation and sliding process of the Yigong landslide under seismic loading.

Initially, studies were conducted based on the datum of climate, topography, and geology, and satellite image of this region, inferring the causes and processes of this landslide [1,2]. Subsequently, field investigations and laboratory tests were carried out by some scholars to study the landslide in a more theoretical and reliable way $[3,4]$. And lately, DEM referencing relative information of the Yigong landslide was widely used to study this landslide, simulating its failure and sliding process and matching well with the actual situation [5-8].

However, DEM is also limited in reflecting the generation and propagation of cracks and small deformation. Therefore, many scholars come to study the hybrid simulation methods that are capable of treating continuous and discontinuous problems. [9] pioneered a hybrid finite-discrete element method, unified the finite element method

1 Corresponding Author, Enlong LIU, State Key Laboratory of Hydraulics and Mountain River Engineering College of Water Resource \& Hydropower, Sichuan University, Chengdu, China; Email: liuenlong@scu.edu.cn. 
based on the constitutive relation and the discrete element method based on the contact law into a computing system. [10][11] adopted FDEM successfully in simulations of acoustic actual geotechnical engineering problems.

The landslide body tends to experience a process from relatively continuous to relatively discontinuous before initiation and damage, which are in accordance with characteristics of the FDEM method. In this paper, a dynamic analysis of the Yigong landslide under seismic loading is conducted with respect to FDEM.

\section{Principles of FDEM}

The FEDM is a combined finite-discrete element method firstly proposed by Mujiza [9], taking advantage of both methods and being able to simulate the process from continuous to discontinuous. The initial computing domain has been discretized into finite elements, and thus continuous deformation can be given concerning the specific constitutive equation. Between each pair of finite elements, zero-thickness joint elements are embedded to realize the transition of finite elements from continuous to discontinuous. A strain-based cohesive cracking model of joint elements, where the bonding stress is proportional to the magnitude of separation of the fracture edges, has been implemented in the FDEM codes. Joint elements will crack and then be removed from the domain once the limited tensile or shear strength is reached according to the strength criterion. These cracks will then evolve to several kinds of fracture resulting in yield or failure of the material. And the discontinuous finite elements without connection by joint elements will be detected by a contact detect algorithm and treated as rigid bodies subsequently. Their contact forces will be calculated a potential function method.

\section{Numerical Simulation of the Landslide}

\subsection{Landslide Description}

Yigong landslide is a giant high-speed landslide that occurred at Zhumulong Gully in Tibet China, depositing the Yigong Zangpo River and forming a dam lake. Its highest point reaches $5,515 \mathrm{~m}$, while Zhamulong gully at $2,185 \mathrm{~m}$ is its lowest point, leading to a height difference of 3,330 meters [3]. Along the gully, the underlying strata are Tertiary Himalayan granite, limestone, and gneiss in turn from top to the bottom [6]. Also, due to a previous landslide in 1900, a large part of the loose material deposition of landslide, originating from the top side, was distributed in the range of $3000-4000 \mathrm{~m}$ above sea level, as shown in figure 1. Thus, both the upper avalanche part and previous landslide part are composed of Tertiary Himalayan granite. In this paper, a section of the Yigong landslide shown in figure 1 has been used to establish the computing model. 


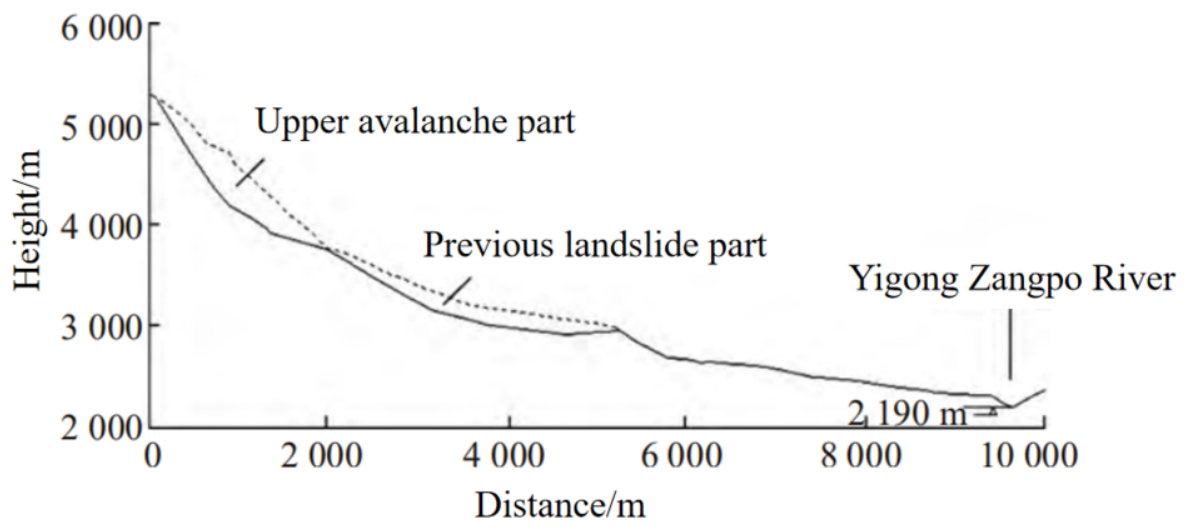

Figure 1. Profile of Yigong Landslide [8]

\subsection{Model Description}

The landslide model, shown in figure 2, was established with LS-PrePost based on the section of Yigong landslide, consisting of 10358 nodes and 2008 finite elements. The mesh size was $200 \mathrm{~m}$ at the part of the landslide bed (the grey part), while a $10 \mathrm{~m}$ size was implemented in the sliding part (red and blue part) to simulate the sliding process more accurately. In figure 2, six reference points A, B, C, D, E, and F are also selected on the surface of the red and blue part of the landslide model in turn from high to low. The bottom is set as fixed while the lateral sides are fixed in the horizontal direction and free in the vertical direction. In this paper, the dynamic analysis of the Yigong landslide was conducted under a seismic load measured in the Wenchuan earthquake. A set of velocity time-history obtained from the acceleration time-history curve of this earthquake (shown in figure 3) was applied to points on the bottom row.

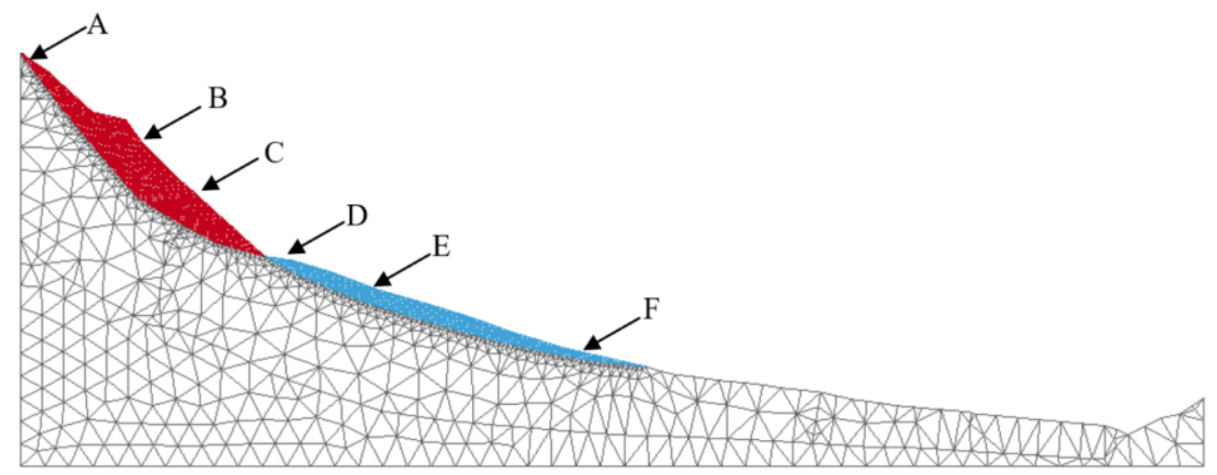

Figure 2. Simulation model of Yigong Landslide 


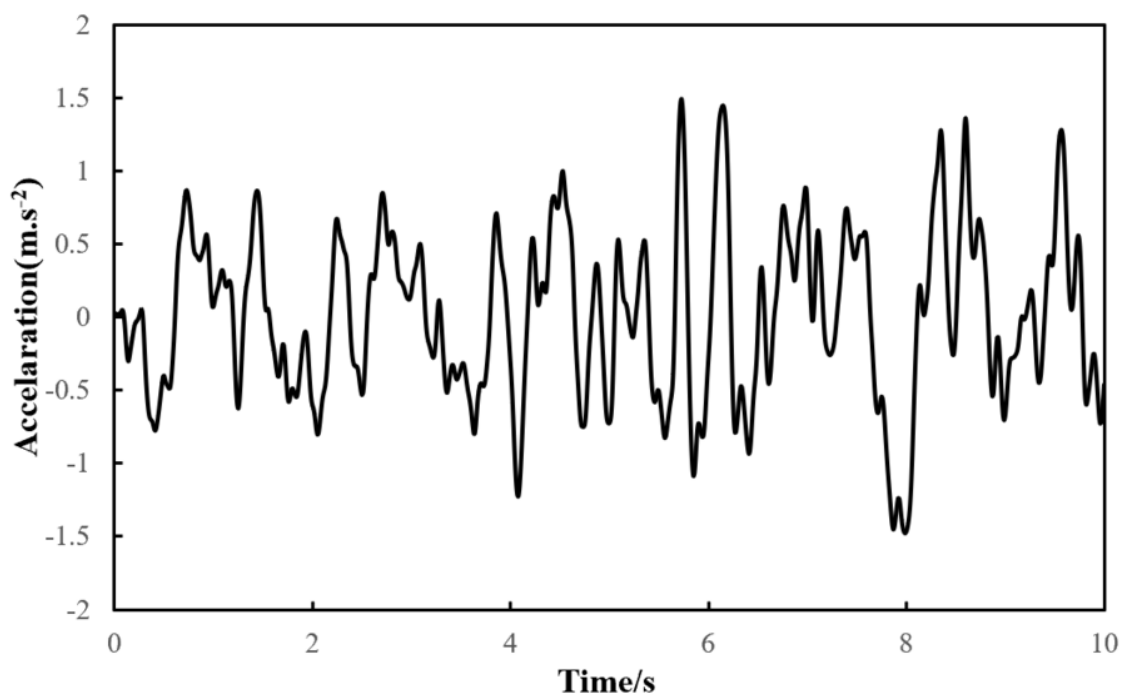

Figure 3. Acceleration Time-History Curve of Measured Seismic Motion in Wenchuan Earthquake

\subsection{Calculation Parameters}

During the simulation, small time steps are required for calculation accuracy and stability, but large memory space and computing time will be at cost. Thus, a time step of $2 \times 10^{-4}$ s and a total step of $6 \times 10^{6}$ are adopted in this paper.

For parameters of finite elements, Lame constants, density, and frictional coefficient are first introduced and will be valued the same as that is used in other simulation methods. Vicious damping is adapted to treat the quasi-static state problems being determined by the following equation $[9,10]$ :

$k s=2 h \sqrt{E \rho}$

where $\mathrm{h}$ is the size of the finite element, $\rho$ is the density, and $\mathrm{E}$ is young's modulus. The normal and tangential penalty function factor, implemented to compute interaction between finite elements, were selected to be $\mathrm{E}$ and $10 \mathrm{E}$, respectively[10].

With regard to parameters of joint elements, they control the fracture behavior of joint elements, thus reflecting the macroscopic behavior of the material. Therefore, tensile strength $f_{t}$, cohesion strength $c$ and fracture energy $G$, can be determined by referencing the corresponding kinds of material. And a fracture penalty factor of $5 \mathrm{E}$ is implemented in this paper [10]. The values of parameters were adapted referencing [12] and listed in table 1 and table 2.

Table 1. Parameters of finite elements in landslide model

\begin{tabular}{cccc}
\hline Parameters & Blue part & Red part & Grey part \\
\hline Lame's constant $\lambda$ & $4.8 \times 109$ & $4.8 \times 109$ & $9.3 \times 109$ \\
Lame's constant $\mu$ & $8.5 \times 109$ & $8.5 \times 109$ & $21.7 \times 109$ \\
Density $\left(\mathrm{kg} / \mathrm{m}^{3}\right)$ & 2616.7 & 2616.7 & 3000 \\
Friction coefficient & 0.2 & 0.2 & 1.4 \\
Normal penalty function factor $(\mathrm{GPa})$ & 20 & 20 & 50 \\
Tangential penalty function factor $(\mathrm{GPa})$ & 200 & 200 & 500 \\
Viscous damping $(\mathrm{kg} /(\mathrm{m} . \mathrm{s}))$ & $1.45 \times 10^{8}$ & $1.45 \times 10^{8}$ & $4.58 \times 10^{9}$ \\
\hline
\end{tabular}


Table 2. Parameters of joint elements in landslide model

\begin{tabular}{cccccc}
\hline Parameters & Blue-Blue & Red-Red & Grey-Grey & Blue-Grey & Red-Grey \\
\hline Tensile strength (MPa) & $5 \times 10^{6}$ & 10 & $8 \times 10^{6}$ & 10 & 10 \\
Cohesion & $1.5 \times 10^{7}$ & 1 & $4 \times 10^{7}$ & 20 & 1 \\
Friction coefficients & 0.18 & 0.1 & 1.19 & 0.1 & 0.1 \\
Fracture energy & 66 & 66 & 30 & 140 & 140 \\
Fracture penalty function factor & 100 & 100 & 175 & 250 & 250 \\
\hline
\end{tabular}

\subsection{Results and Analysis}

The results of the landslide simulation are exhibited below in terms of the distance in $\mathrm{X}$ direction and velocity of reference points as shown in figure 4.

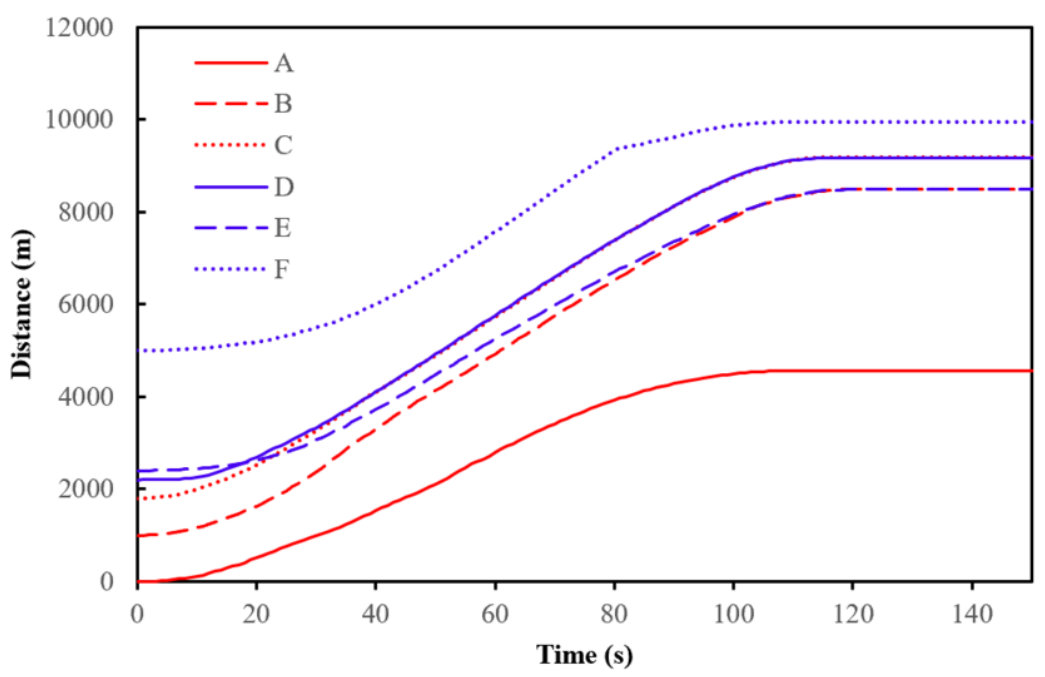

Figure 4. Distance of reference points in sliding process

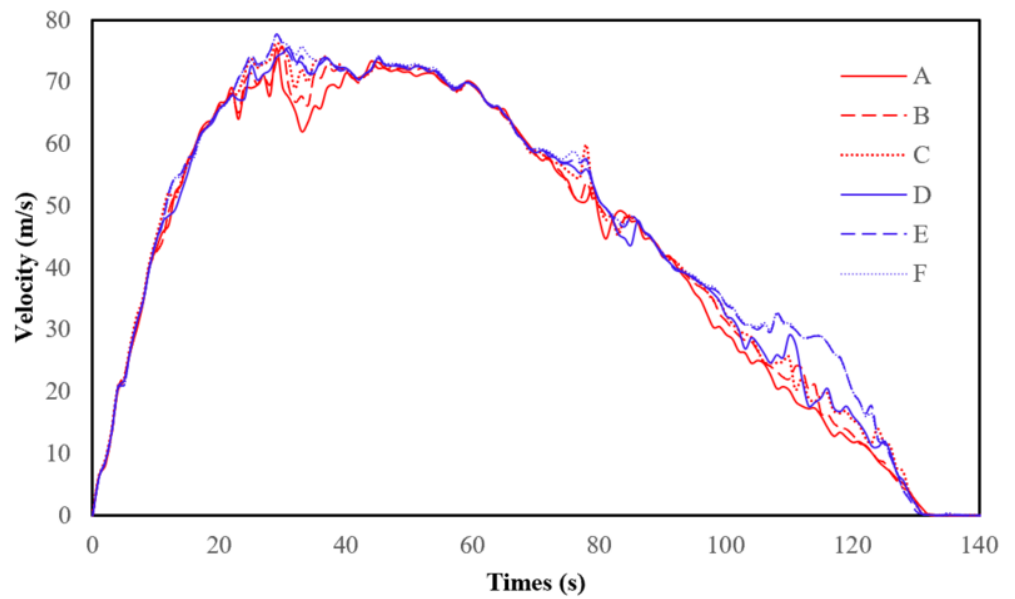

Figure 5. Velocity time-history of reference points in sliding process 
As shown in figure 4, the Distance-Time curve of reference points A, B and C are depicted in red as distributing in the red part of the model, representing the previous landslide part; while D, E and F are in blue for a similar reason. With different initial values, distances of six reference points increase gradually and eventually to final values. Note that two pairs of curves possess common values of distance and overlap after 120s in figure 4. Moreover, each pair of curves is composed of a red one and a blue one, reflecting the same final position of the points belonging to the upper avalanche part and the previous landslide part, respectively. That is in accordance with the real distribution of accumulated material of field investigation in some papers. [3,8,13] found the accumulation of this landslide is block rock from the upper avalanche part, a mixture of the upper avalanche part and the previous landslide part, and detrital material from the previous landslide part, respectively, from top to bottom. Simulation results of distance are in good agreement with the result of material accumulation in the field investigation.

Figure 5 demonstrated the velocity time-history of six reference points, among which three red curves represent the points in the upper avalanche part and three blue curves represent the points in the previous landslide part. An overall accelerationdeceleration-acceleration trend can be captured from the red curves of figure 5, while the blue curves only possess an over trend of acceleration-deceleration. The two different trends of different parts are in accord with the sliding process of the Yigong landslide proposed in some papers $[8,14,15]$. During this process, the upper avalanche part will initiate and accelerate first, and then decelerate on account of the obstruction of the previous landslide part; while the previous landslide part will accelerate under the action of the upper avalanche part. They finally reach a common speed and decelerate to slide down. Simulation results of velocity agree with the sliding process.

Moreover, from both of the figures, inconsistency of displacements and velocity of different points are seen during the sliding process, resulting in the tensile, shear, and bulging cracks among the landslide body (shown in figure 6). That seems to be the main reason for the initiation of this landslide. Therefore, the FDEM method can reproduce and describe the cracks, displacements, and velocity of the landslide well.

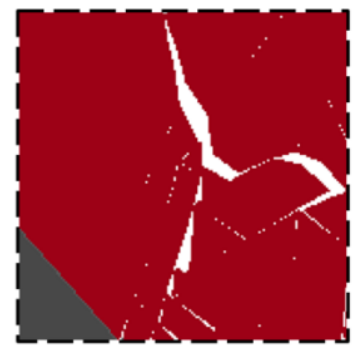

(a) Tensile crack

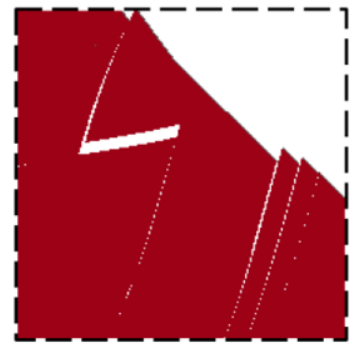

(b) Bugling crack

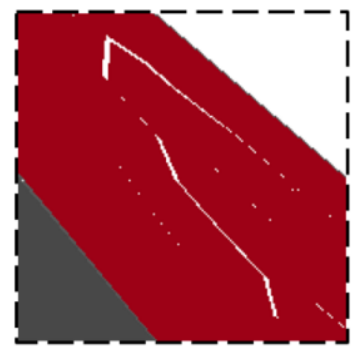

(c) Shear crack

Figure 6. Three kinds of cracks in simulation

\section{Conclusions}

(1) The final distribution of reference points, obtained from adding initial position and displacements, are shown a regularity that red points, overlapping red and blue points and blue point accumulates from near to far in turn. That is 
in good agreement with an accumulation of different landslide parts in the field investigation.

(2) The velocity time-history curves of reference points of different landslide parts possess different kinds of trends, matching well with the sliding process of the Yigong landslide proposed earlier.

(3) The FDEM method can well describe the formation and propagation of various kinds of cracks of landslide under seismic load, revealing the applicability and superiority of this method to other continuous-discontinuous problems.

\section{Reference}

[1] Ren JW, Shan JJ, Shen J, Ge S, Zha S, DENG GY, ZHANG J, Suo R (2001) Geological geomorphology and kinematic characteristics of collapse-landslide-debris flow in Yigong, Tibet. Geological Review 06,642-647. (in Chinese)

[2] Wang Z. A thunder at the beginning of the 21 st century-The giant Yigong Landslide. In: The Tenth International Symposium on Landslides and Engineered Slopes. Xi'an, Shaanxi, China; 2008, Xi'an, Shaanxi, China, 2008:8.

[3] Xu Q, Shang Y, van Asch T, Wang S, Zhang Z, Dong X. 2012Observations from the large, rapid Yigong rock slide - debris avalanche, southeast Tibet. Can Geotech J;49:589-606.

[4] Hu M J, Wang F W, Cheng Q G. 2009 Experimental exploration on the formation causes of Yigong giant landslide based on high-speed ring shear test. Journal of Geotechnical Engineering; 31:16021606.

[5] Zhou G, Roque P, Xie Y, Song D, Chen H. 2020Numerical study on the evolution process of a geohazards chain resulting from the Yigong landslide. Landslides.

[6] Zhou JW, Cui P, Hao MH. 2016Comprehensive analyses of the initiation and entrainment processes of the 2000 Yigong catastrophic landslide in Tibet, China. Landslides;13:39-54.

[7] Zhuang Y, Yin Y, Xing A, Jin K. 2020Combined numerical investigation of the Yigong rock slidedebris avalanche and subsequent dam-break flood propagation in Tibet, China. Landslides.

[8] Liu G Y, Xu W J, Tong B, Wang L C. 2019 High speed and remote landslide disaster dynamics based on block discrete element. Chinese Journal of Rock Mechanics and Engineering; 38:15571566.

[9] Munjiza A. 2004The combined finite-discrete element method: The combined finite-discrete element method.

[10] Mahabadi OK. 2012Investigating the Influence of Micro-scale Heterogeneity and Microstructure on the Failure and Mechanical Behaviour of Geomaterials. Doctoral.

[11] Lisjak A. 2014Investigating the Influence of Mechanical anisotropy on the Fracturing Behaviour of Brittle Clay Shales with Application to Deep Geological Repositories.

[12] Su Y, Liu EL. 2019Numerical Simulation of Dynamic Analysis of Glacier Under Seismic Loading Based on Combined Finite-Discrete Method. IOP Conference Series: Earth and Environmental Science;283:12064.

[13] Xu Q, Y S, Asch TV, Wang S, Zhang Z, Dong X. 2012Observations from the large, rapid Yigong rock slide - debris avalanche, southeast Tibet. Revue Canadienne De Géotechnique;49:589-606.

[14] Liu W. Analysis of geological hazard chain characteristics of giant ultra-high speed long distance landslide in Yigong, Xizang province in 2002. Chinese Journal of Geohazards and Prevention:11-20.

[15] Yin Y 2000 Survey of high-speed giant landslide in Yigong, Bomi, Tibet. Chinese Journal of Geohazards and Prevention: 103. 